\title{
EPISTAXIS: AN AETIOCLINICOPATHOLOGICAL STUDY IN HOSPITALISED PATIENTS
}

\author{
Nandakumar Choorakkattukara Raman ${ }^{1}$
}

${ }^{1}$ Assistant Professor, Department of ENT, Government Medical College, Thrissur, Kerala State.

ABSTRACT

\section{OBJECTIVE}

To find out the aetioclinicopathological features of epistaxis in hospitalised patients.

\section{SETTINGS AND DESIGN}

It is a single group cohort study conducted in the Department of Government Medical College, Thrissur, Kerala, during the period of April 2011 to April 2012. Study included 50 hospitalised patients. Patients were selected based on inclusion and exclusion criteria. Inclusion criteria: 1] Both male and female patients, 2] Only admitted patients. Exclusion criteria: 1] Patients treated as outpatient and 2] Those treated for same complaints previously.

\section{METHOD}

All 50 patients were subjected to detailed clinical examination, routine and relevant blood examinations, X-ray PNS, X-ray nasal bone-lateral view and DNE-Diagnostic Nasal Endoscopy. CT-PNS and MRI were taken depending on suspected causes. Patients were treated according to their causes using non-surgical and surgical methods. Patients were followed up for 6 months.

\section{RESULT}

Analysis found that most common group affected is patients at the age of 51-60, and the most common cause found was hypertension.

\section{CONCLUSION}

Epistaxis is one of the common emergencies in ENT practice, caused by simple and serious causes. So it should be treated with utmost importance and care depending upon the situation.

\section{KEYWORDS}

Deviated Nasal Septum, Fracture Nasal Bone, Idiopathic, Nasal Pack.

HOW TO CITE THIS ARTICLE: Raman NC. Epistaxis: an aetioclinicopathological study in hospitalised patients. J. Evolution Med. Dent. Sci. 2016;5(67):4797-4800, DOI: 10.14260/jemds/2016/1093

\section{INTRODUCTION}

Epistaxis is a common clinical problem and one of the most frequent emergencies in ENT practice; $60 \%$ of people are thought to have nasal bleeding at least once in their lives. Although death from epistaxis is rare, it can occur and a significant morbidity is relatively common. It is an alteration of normal haemostasis in the nose. It is defined as bleeding from nose, even though the actual meaning of word epistaxis is bleeding from above.

"Nose bleeds occur in those who are beginning to have feelings of best or who are getting the signs of manliness." $-4^{\text {th }}$ century BC-Hippocrates. ${ }^{1}$ Earliest references to the treatment of epistaxis are by "Aradmana"1 surgeon to Assyrian court over 2500 years ago. Hippocrates ${ }^{1}$ in $4^{\text {th }}$ century BC found that pressure on alae nasi was an effective method of controlling nose bleed and he recommended packing in selected cases. He treated prolonged bleeding with the application of cold towels to the shaven head.

Hippocrates ${ }^{1}$ was the first to describe "vicarious menstruation." Heraclides ${ }^{1}$ in first century BC combined an anterior nasal pack with digital pressure on soft palate in order to prevent blood escaping posterior to oropharynx.

Financial or Other, Competing Interest: None.

Submission 09-07-2016, Peer Review 02-08-2016,

Acceptance 08-08-2016, Published 20-08-2016.

Corresponding Author:

Dr. Nandakumar Choorakkattukara Raman,

'Nandanam,' Pottore Post,

Thrissur-680581,

Kerala State.

E-mail: drnandakumargmctcr@gmail.com

DOI: $10.14260 /$ jemds/2016/1093
Many local applications were tried including dung, burnt egg, burnt blood, vitriol, muscles and 'mummia,'2 the resins used for embalming Egyptian mummies. Mohammed ${ }^{3}$ [188081] who developed Sphygmomanometer told "if nose of old people with high arterial pressure did not bleed, their brain would." James Little 4 and Kisselbach ${ }^{4}$ [1879 and 1880] described the common site of bleeding as being at the caudal end of the septum. The area now known as "Little's Area, ${ }^{4}$ " has variously been known as "Organos Cort," "Glandula Virchow, 4" "Locus Valsalvae," "Locus Kiesselbach,4" the correct eponym hotly debated in the past.

"Zukerkandl3" [1892] and "Burnham"5,3 indicated that blood supply of turbinate is exclusively derived from external carotid artery. "Ball1" [1760] suggested the use of cautery directly to the vessel using a cannula to protect the alar rim. The principles of "Hippocrates 1 " postnasal pack was successfully applied by "Henri be Dran ${ }^{1,3}$ " in $18^{\text {th }}$ century. He passed forceps through nose and grasped a shoe lace held in nasopharynx by his index finger, which was used to pull packing to post nasal space.

The first attempt of arterial ligation was made in 1868 by "Pilz6,7" of Bresslan, who tied common carotid7 artery. "Sieffert6,7" in 1928 ligated internal maxillary artery ${ }^{6}$ via transantral approach, while "Good Year6,7" in 1937 tied anterior ethmoidal artery for first time. "Vanwyck, Vinnela and Heeneman $^{8}$ in 1982 carried out therapeutic embolisation ${ }^{8}$ under selective angiographic control. It was "Hirchmann ${ }^{3,1}$ " in 1901 who introduced the technique of nasal endoscopy ${ }^{9,10,11}$ with a modified cystoscope. 


\section{MATERIALS AND METHODS}

50 consecutive patients who had admitted for the management of epistaxis were selected for the study. Patients were selected as per following inclusion and exclusion criteria. Inclusion criteria are, 1] Both male and female patients and 2] Only admitted patients. Exclusion criteria are, 1] Patients treated as outpatient and 2] Patients undergone treatment for same complaints previously. All were subjected to detailed history taking, clinical examination and investigations like routine and relevant blood examinations, X-ray PNS. CT - nose and PNS and MRI were done according to the suspected causes of epistaxis. DNE10,11,12 diagnostic nasal endoscopy was done in all patients under Local Anaesthesia; 10 patients underwent CT nose and PNS, of which 2 showed fracture maxilla and 8 showed other lesions. Only one underwent MRI, which showed a differential diagnosis of olfactory neuroblastoma and rhabdomyosarcoma.

All of them were treated either by non-surgical or surgical methods like anterior nasal packing, posterior nasal packing or both. Nonsurgical methods also included application of local pressure, anti-hypertensives, antihistamines, decongestants and antibiotics. Surgical method includes removal or correction of lesion in the nose or sinuses. All patients were followed up for 6 months.

\section{RESULTS AND OBSERVATIONS}

Out of 50 patients studied, 32 patients were males and 18 patients were females giving a male:female ratio of 1.7:1. Most common age group was 51-60 years and next was 41-50. Bleeding was unilateral in 18 patients, while it was bilateral in 32 patients. Bleeding was anterior in 10 patients, while 40 patients had both anterior and posterior nasal bleeding. Longest duration of epistaxis was in a 30-year-old male who had recurrent bouts of epistaxis over a period of 4 months. He was diagnosed to have unilateral rhinosporidiosis.

One boy of 5-year-old presented with unilateral epistaxis showed a mass in the roof of nasopharynx diagnosed by MRI with 2 differential diagnosis - Olfactory neuroblastoma and Rhabdomyosarcoma. Finally, histopathological report after surgical excision came as "Juvenile active ossifying fibroma," which is a benign tumour. One female patient aged 56 was diagnosed to have "Malignant melanoma" who presented with unilateral mass leading to recurrent episodes of epistaxis. Another female patient of 45 years presented with recurrent episodes of epistaxis was found to have Rhinolith, which was removed under General Anaesthesia intranasally. Two middle aged patients with frequent episodes of epistaxis underwent surgery for the removal of Rhinosporidial mass transnasally with cauterisation at the base.

Only 2 cases [4\%] were found idiopathic even after doing all investigations. Epistaxis caused by sinusitis was seen in 1 patient only and it was relieved by surgery. Most common cause of epistaxis in this study was Hypertension. ${ }^{13}$ Out of 22 hypertensive epistaxis patients, 16 were known hypertensives on treatment which was regular in 10 patients and irregular in 6; Hypertension was detected only at the time of admission in 6 patients; 16 were given only anterior nasal packing, while 6 were given both. No one was given repacking or blood transfusion.
Fifteen patients showed fractured nasal bone of which one was compound. Two patients showed fracture of the maxilla with hemosinus. All traumatic patients underwent X-ray PNS and X-ray nasal bone - lateral view of which 13 showed fractured nasal bone. But CT-PNS was necessary in 5 patients only and 2 of them showed fracture of the maxilla. Deviation of septum with spur caused epistaxis only in 4 patients and underwent septal correction. One patient presented with epistaxis from a reddish mass in the floor and lateral wall of nostril, which was surgically removed and HPR came as "Pleomorphic adenoma."

Twenty six patients had only a single episode of epistaxis, while 19 patients had 2-5 episodes before seeking admission in the hospital. But 5 patients had more than 5 episodes of bleeding before hospitalisation. Abnormal coagulation ${ }^{14}$ profile was found in no patients.

\begin{tabular}{|c|c|}
\hline Age in Years & $\begin{array}{c}\text { Percentage of } \\
\text { Patients }\end{array}$ \\
\hline $0-10$ & $2 \%$ \\
\hline $11-20$ & $6 \%$ \\
\hline $21-30$ & $18 \%$ \\
\hline $31-40$ & $14 \%$ \\
\hline $41-50$ & $22 \%$ \\
\hline $51-60$ & $28 \%$ \\
\hline $61-70$ & $6 \%$ \\
\hline $71-80$ & $4 \%$ \\
\hline $81-90$ & 0 \\
\hline \multicolumn{2}{|c|}{ Table 1 } \\
\hline \multicolumn{2}{|c}{} \\
\hline
\end{tabular}

\begin{tabular}{|c|c|}
\hline Diagnosis & No. of Patients \\
\hline Hypertension & 22 \\
\hline Fracture nasal bone + maxilla & 15 \\
\hline Deviated nasal septum & 4 \\
\hline Rhinosporidiosis & 2 \\
\hline Idiopathic & 2 \\
\hline Rhinolith & 1 \\
\hline Sinusitis & 1 \\
\hline Malignant melanoma & 1 \\
\hline Pleomorphic adenoma & 1 \\
\hline Juvenile active ossifying fibroma & 1 \\
\hline Table 2 \\
\hline
\end{tabular}

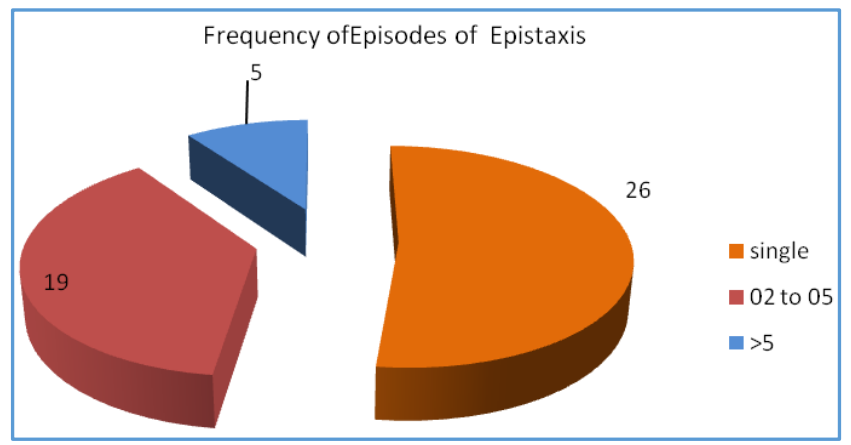

Fig. 1: Frequency of Episodes of Epistaxis 


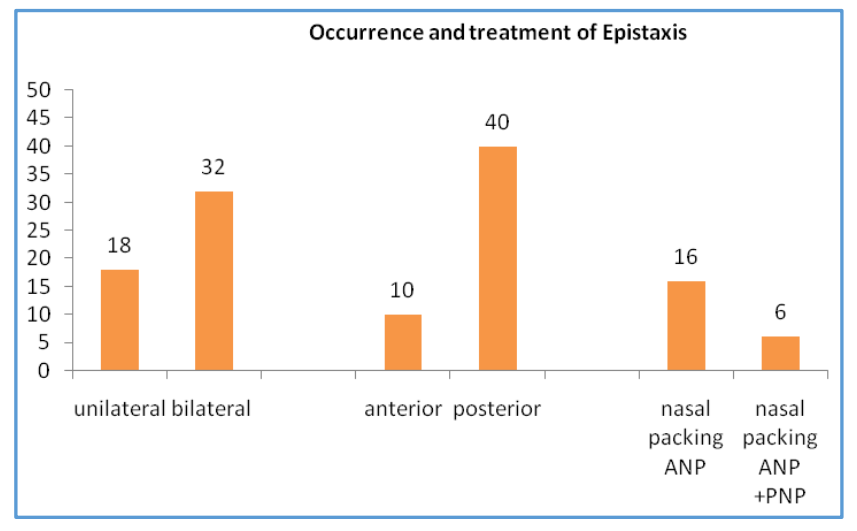

Fig. 2: Occurrence and Treatment of Epistaxis

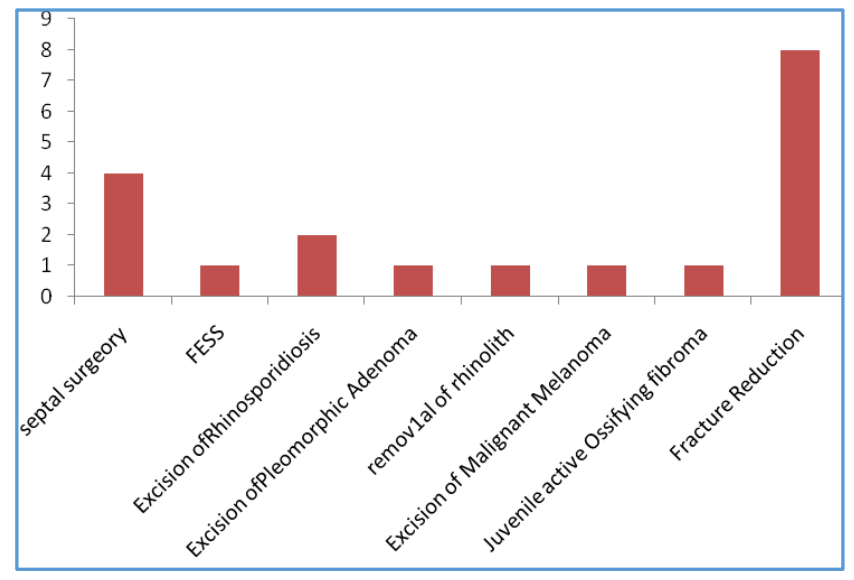

Fig. 3: Surginal Treatment Offered

\section{DISCUSSION}

As per this study, 64\% patients were males and $36 \%$ were females giving a male:female ratio 1.7:1. This male predominance is similar to that reported by Safaya. ${ }^{12}$ Study by Nighel Padgham,15 Monux ${ }^{2}$ et al also shows a male predominance. Age wise distribution in the study shows peak incidence between 51-60 years [28\%]. Holger Juselius ${ }^{16}$ also has reported maximum incidence in old age group, i.e. 60-69 years. Most common associated symptom ${ }^{17}$ was nasal obstruction which was present in $25 \%$ followed by headache in $22 \%$ patients. Rest of them were having no associated complaints. Majority bleeding was bilateral [64\%] and it was due to hypertension ${ }^{13}$ and trauma; $52 \%$ patients had mild bleeding and $48 \%$ showed severe bleeding. But the exact comparison of amount of bleeding is not possible because of lack of universally accepted criteria for grouping into mild and severe bleeding. So the only way to measure the severity is to correlate with haemoglobin ${ }^{14}$ level done at the time of presentation. It was more than $10 \mathrm{gm} \%$ in $52 \%$ patients and 6$10 \%$ in $48 \%$ patients. The study shows a correlation between the amount of bleeding and cause of bleeding. In the cases of hypertension, ${ }^{11}$ bleeding was severe in all patients, but in the cases of septal deviation bleeding was mild. Fractured nasal bone and maxilla showed severe bleeding in a few numbers, 2 out of 15 .

Thus, it is evident that the amount of bleeding due to hypertension ${ }^{11}$ tend to be on higher side, while that due to septal deviation and sinusitis is on lower side. This is due to pathophysiology ${ }^{5}$ of each disease. Hypertension ${ }^{11}$ is a disease of middle and older age groups whose nasal arteries show progressive replacement of mucosal tissue in the tunica media by collagen. 1,5

The incidence of neoplasm in this study is this study is 6\% when compared to $2 \%$ reported by Nigel Padgham. 15 No vascular mass like nasopharyngeal angiofibroma was reported in this study. Thaha 14 in his study reported $8.3 \%$ abnormal coagulation profile. He opines that coagulation study should be performed only when clinically indicated, because in his study abnormal coagulation results were due to warfarin and/or aspirin. The association of hypertension ${ }^{11}$ with epistaxis in this study is $44 \%$ and it is almost similar to that of Holger Juselius, ${ }^{2}$ which is $47 \%$. Not even a single case of refractory epistaxis was reported in this study. ${ }^{17 "}$ Finally, it is seen that there good similarity exists in the findings between this study and large series studies by Safaya. ${ }^{12}$ Nigel Padgham,18 Holger Juselius ${ }^{2}$ and Monux ${ }^{3}$ et al etc.

\section{CONCLUSIONS}

Epistaxis is one of the common emergencies in ENT practice caused by simple and serious causes. It affects old and middle aged patients, mainly with a male predominance. Most common cause in this study is hypertension ${ }^{11}$ followed by trauma. Septal deviation is also found to be one of the major causes. Idiopathic ${ }^{7}$ epistaxis is found to be small in number, so all patients with history of epistaxis should be evaluated thoroughly by doing all investigations to exclude serious like juvenile nasopharyngeal angiofibroma, leukaemia, ${ }^{14}$ cirrhosis, etc., even though this study does not show any such cases. All patients should be offered therapeutic measures either surgically or non-surgically ${ }^{19}$ like excision of lesions, septal correction, endoscopic sinus surgery, ${ }^{6}$ etc. and nasal packing [both anterior and posterior] anti-hypertensives, antihistamines, decongestants, antibiotics, etc. Recurrence should be expected in hypertensive ${ }^{11}$ patients and rhinosporidial cases, which may be due to stoppage of regular medicine and incomplete removal of lesion. Number of idiopathic epistaxis is few and it may also recur. So all epistaxis patients should be investigated in detail and treated with utmost importance and care depending upon the situation.

\section{REFERENCES}

1. Burnham HH. An anatomical investigation of blood vessels of lateral wall of nose \& their relation to turbinates and sinuses. J laryngol and otol 1935;50:569-93.

2. Monux A, Tomas $\mathrm{M}$, Kaiser $\mathrm{C}$, et al. Conservative management of epistaxis. J Laryngol and Otol 1990;104(11):868-70.

3. El- Silin O. Endonasal endoscopy and posterior epistaxis. Rhinology 1993;31:119-20.

4. Mackenzie D. Little's area or Locus Kiesselbach. J Otol Laryngol 1941;1:21-2.

5. Burnham HH. An anatomical investigation of blood vessels of lateral wall of nose \& their relation to turbinates and sinuses. J Laryngol and Otol 1935;50(8):569-93.

6. Laughran S, Hilmi O, McGarry GW. Endoscopic sphenopalatine artery ligation - when, why and how to do it? Clin Otolaryngol 2005;30(6):539-43.

7. Waldron J, Stafford N. Ligation of external carotid artery for severe epistaxis. J Otolaryngol 1992;21(4):249-51.

8. Scaramuzzi N, Walsh RM, Brennan P, et al. Treatment of intractable epistaxis using arterial embolization. Clin Otol aryngol 2001;26(4):307-9. 
9. El-Silimy 0. Endonasal endoscopy and posterior epistaxis. Rhinology 1993;31(3):119-20.

10. Lloreute JL, Suárez C, Moro M, et al. Diagnostic biopsy with paranasal sinus endoscopy. Acta Otorrinolaryngol Esp 1998;49(2):129-32.

11. Gustafson RO, Kern EB. Office endoscopy - when, why, what and how. Otolaryngol Clin North America 1989;22(4):683-9.

12. Safaya A, Venkatachalam VP, Choudhury N. Nasal endoscopy-evaluation in epistaxis. Indian J Otolaryngol Head \& Neck Sur 2000;52(2):133-6.

13. Weiss NS. Relation of high blood pressure to headache, epistaxis and selected other symptoms. The United States health examination survey of adults. New England J Med 1972;287(13):631-3.

14. Thaha MA, Nilssen EL, Holland S, et al. Routine coagulation screening in the management of emergency admission for epistaxis - is it necessary? J laryngol Otol 2000;114(1):3840.
15. Padgham N. Epistaxis, anatomical and clinical correlates. J Laryngol Otol 1990;104(4):308-11.

16. Juselius $H$. Epistaxis, a clinical study of 1,724 patients. J Laryngol Otol 1974;88(4):317-27.

17. Danielides V, Kontogiannis N, Bartzokas A, et al. The influence of meteorological factors on the frequency of epistaxis. Clin Otolaryngol Allied Sci 2002;27(2):84-8.

18. Schaitkin B, Strauss M, Houck JR. Epistaxis: medical versus surgical therapy: a comparison of efficacy, complication and economic considerations. Laryngoscope 1987;97(12):1392-6.

19. McGarry GW, Gatehouse S, Vernham G. Idiopathic epistaxis, hemostasis and alcohol. Clin Otolaryngol Allied Sci 1995;20(2):174-7. 